\title{
Wireless management system of prefabricated construction materials based on BIM technology
}

\author{
Xinhua Wu
}

\author{
*Correspondence: \\ skd992813@sdust.edu.cn \\ College of Resources, \\ Shandong University \\ of Science and Technology, \\ Taian 271019, Shandong, \\ China
}

\begin{abstract}
The primary goal of material management is to arrange the use of materials reasonably, which is particularly important for the construction industry. Wireless communication can transmit a lot of information in time in production, which can promote the management and arrangement of building materials. In order to explore the management method of prefabricated materials, this paper compares the prefabricated building materials management based on BIM with the traditional method and the management method combining BIM and wireless communication through sampling survey and sand table simulation. This paper compares the material procurement, storage and quality in the construction stage and analyzes the material management differences of different technical methods in different stages. The results show that the average inventory turnover rate of BIM-based management method is 6 times, and that of conventional method is 4 times. However, in the construction stage, the gap between the two methods is narrowed. The combination of wireless communication and BIM leads the whole process in inventory turnover rate. The turnover times of prefabricated building materials management method based on BIM Technology is reduced to 3 times, and that of conventional method is reduced to 2 times. However, the turnover times of BIM combined with wireless communication is more than 4 times. Therefore, BIM-based prefabricated building materials management can reduce the use of funds and the occupation of warehouse, and control the quality of materials better than the traditional methods. However, the combination of BIM and wireless communication can achieve better results.
\end{abstract}

Keywords: BIM technology, Prefabricated building, Material management, Inventory turnover times

\section{Introduction}

China's urban and rural construction area is about 2 billion $\mathrm{m}^{2}$ each year, which is the largest construction market in the world. However, there are a series of problems in China's construction industry, such as large energy consumption, poor quality, long cycle, high cost and nonenvironmental protection, so it is urgent to take modern measures to promote the transformation and upgrading of the construction industry. The development of industry is not only dependent on industrial technology, but also needs

c) The Author(s), 2021. Open Access This article is licensed under a Creative Commons Attribution 4.0 International License, which permits use, sharing, adaptation, distribution and reproduction in any medium or format, as long as you give appropriate credit to the original author(s) and the source, provide a link to the Creative Commons licence, and indicate if changes were made. The images or other third party material in this article are included in the article's Creative Commons licence, unless indicated otherwise in a credit line to the material. If material is not included in the article's Creative Commons licence and your intended use is not permitted by statutory regulation or exceeds the permitted use, you will need to obtain permission directly from the copyright holder. To view a copy of this licence, visit http:// creativecommons.org/licenses/by/4.0/. 
information exchange. Especially in the process of industrial production, industrial control needs timely and effective information, and wireless communication technology realizes real-time and effective industrial control in industrial production, which provides new vitality for the development of industry, especially in the management of building materials; wireless communication can play a great role in promoting.

Wireless communication technology is a kind of wireless access, so it has the characteristics of flexibility, quickness and high efficiency. It can transmit data image and text voice directly without the limitation of time and space. It plays an increasingly important role in industrial development. In the field of industrial automation, there are many sensors, PLC, computers, card readers and so on. The connection and information transmission of these devices need a control network. The communication interface provided by these devices is usually RS-232 or RS- 485 . The devices with these interfaces are connected together by wireless LAN, and the signals are converted to each other by the network. In this way, the communication ability of the industrial equipment is continuously strengthened, and the information processing ability is greatly improved. Moreover, the wireless local area network covers a wide range, which plays an important role in the modern industrial automation production [1].

With the help of BIM technology, we can avoid the construction problems of prefabricated buildings, such as "mistakes, omissions, collisions and shortages," realize the integrated collaborative management from design to operation and maintenance of prefabricated buildings and effectively improve the overall construction and management level of prefabricated buildings. There are still many difficulties in the application of BIM technology in prefabricated building, such as imperfect technical standards and low industry recognition. To achieve the seamless combination of BIM technology and prefabricated building, it needs to be further improved in practice. Based on the characteristics and shortcomings of prefabricated buildings in China, Yan constructed the integrated management mode of prefabricated building projects by combining BIM technology and integrated management theory. Then, from the perspective of goal integration, organization integration and process integration, this paper analyzes the construction principles of assembly building project-integrated management mode and discusses the operation process, information integration and information interaction of assembly building project-integrated management mode from the perspective of information classification, and then puts forward suggestions on the application of BIM-integrated management process of prefabricated building. His theory is conducive to promote the integration and optimization of construction enterprise resources and promote the development of the whole industry [2]. In order to improve the design level and design efficiency of domestic fashion designers, and solve the severe challenges faced by the management and use of advanced information technology tool BIM technology in domestic fashion design, Zhang Lin, from the perspective of strategic development, established a set of home decoration design system based on BIM technology, carried out unified three-dimensional home decoration design, unified price management, and a complete enterprise knowledge management foundation is established, and the domestic clothing design quantity management system is calculated from the design drawings. The application of BIM technology in home decoration industry is helpful to promote the development of 
scale economy of domestic garment enterprises, especially to improve the competitiveness of enterprises in the field of home decoration design tools. His theory is that under the implementation of the design system based on BIM technology in home decoration design company, the problem of single design tool and centralized management of enterprise resources in traditional decoration design industry is solved. The 3D decoration design based on BIM technology tool is realized, and the design resources are managed uniformly, which has accumulated into an intangible asset of a clothing enterprise for a long time and improves the efficiency of domestic fashion design rate and the competitiveness of decoration enterprises. However, his research lacks a certain practical basis and cannot see its advantages and disadvantages from the most essential point of view of society, so it is not very convincing [3]. BIM technology has changed the way people acquire and transmit information in traditional projects; according to the classification of building intelligence alliance of America, there are 25 listed persons in the application of BIM in construction engineering. Analyzing all participants of construction projects, including architectural planners, owners, contractors, property management companies and construction supervision companies, the construction supervision company is the most suitable organization technology to promote BIM. In addition, Shi also proposed the establishment of BIM technology consulting, expanding the business coverage of the existing supervision company, BIM consulting, including the supervision business into BIM consulting and combining the supervision company with BIM consulting, which to a large extent belongs to the innovation of traditional technology and conforms to the development of the times and the trend of social development [4].

In this paper, sand table simulation method is used to carry out prefabricated building test. The material management method based on BIM technology is compared with the traditional method, and the material management method of BIM technology is combined with wireless communication to compare the difference between the two methods. Through the comparison of construction methods, the most suitable logistics management mode and the most suitable construction method are found.

\section{Methods}

\subsection{BIM technology}

BIM technology, namely building information model, is a new type of information technology. The carrier of this technology is building model, which can collect and process various information and real data of construction projects, and guide the construction and design management of related construction projects with the application of informatization. This technology is mainly used in engineering design and management, integrating the relevant information of each project in the parameter model, sharing and transferring the project operation, maintenance and planning process, so that the technical personnel can correctly understand all kinds of building information and make efficient response measures. It plays an extremely important role in saving costs, shortening construction period and improving production efficiency $[5,6]$.

1. Features of BIM 
1. Visualization, in the construction industry, the characteristics of visualization play a very important role in the application of the construction industry. For example, in the construction drawing, the information expression of each component in the drawing is simply drawn on the drawing with lines, and the real structural form of this drawing needs professional personnel to explore [7]. For the simple and easy to understand things, this kind of imagination is feasible. However, with the diversification of architectural forms in the construction industry in recent years, and the continuous introduction of complex modeling, it makes the things that only rely on human brain to imagine become a little inadequate. Therefore, under the visualization of BIM technology, the traditional obsolete line-type components are transformed into three-dimensional physical graphics to display. In the construction industry, there are also design renderings, but such renderings are usually produced by professional production teams under the bar information, not by the information of components. There is a lack of feedback and interaction between the same components. The visualization in BIM has a strong feedback and interaction between the same components. Each process in BIM building information model is visualized. This result can not only be used to show the effect and generate reports, but also, most importantly, the discussion, decision-making and communication of project operation, design and construction process are carried out in such a state, which will be more transparent and clear [8,9].

2. Coordination, both the design and owner units, and the construction units are doing coordination and coordination work, which is the key content in the construction industry. However, when the project encounters implementation problems, it is necessary to organize relevant personnel to hold a coordination meeting to find out the causes of the construction problems and find solutions, and then make corresponding remedial measures for the construction changes [10]. However, the coordinated solution has a certain lag. In the design of the project, the communication between the designers may not be very smooth, so there are various knowledge collision problems. For example, in the piping layout of HVAC and other specialties, because the construction drawings are different, in the real construction, there may be conflicts between the beam of structural design and the pipeline layout. This kind of problem is often encountered in daily construction, but it can only be handled after the problem appears. The coordination of BIM technology can solve this problem well, that is, BIM building information model can coordinate the collision problems of various disciplines in the early stage, generate and provide coordination data. The coordination function of BIM technology is not only the collision between different disciplines, but also plays a great role in promoting the layout of elevator shaft, fire compartment and underground drainage layout.

3. Simulation, the simulation of BIM technology refers to the simulation of things that cannot be operated in the real world. In the design stage of BIM, it can also carry out simulation experiments on some design things, such as emergency evacuation simulation, energy-saving simulation, heat conduction simulation, sunshine simulation. Moreover, 4D simulation in the construction and bidding 
stage, that is, the actual construction, is simulated by the construction organization design, so as to find the most suitable construction scheme for construction more clearly. At the same time, the 5D simulation experiment (based on the cost control of 3D model) will better control the cost, and the handling mode of daily emergency can be simulated in the operation stage, for example, fire personnel evacuation or earthquake escape simulation [11].

2. Application of BIM

1. BIM technology is applied to the architectural design stage. The technology is based on 3D modeling, and the information database is established by parametric design. The presentation form is mainly database. There are three stages in the establishment of BIM model, including standard formulation, model establishment and model application [7, 12]. Each graphic unit in the model has parameters such as size, type, material. The parameters control all component models, which helps to realize the relevance of BIM model. When a parameter in a component changes, other components related to it will be updated accordingly, and the omissions, errors and even information inconsistency between drawings will be solved. Collaborative management and information technology is the greatest value of BIM technology. The design models of various disciplines are integrated on the same platform, which makes the collaborative effect between the participants and the disciplines possible.

2. Cost management and engineering quantity statistics, in the traditional era, cost personnel have to spend a lot of energy and time in the statistical engineering quantity, but the cost accuracy is not very high. On the contrary, in BIM technology, because it is a database with a large amount of building information, the engineering quantity can be quickly calculated and counted by computer in the database. This eliminates the calculation error caused by manual operation [13]. The combination of BIM and Internet of things technology can ensure the quality of components, and it is more convenient to manage the transportation, construction, production and storage, operation and maintenance process of components, and also meet the needs of users.

3. BIM is used in the operation and maintenance stage. With the more and more extensive use of the Internet of things, BIM technology also ushers in new challenges in the operation and maintenance stage of prefabricated buildings. For example, in case of a sudden fire, BIM technology will automatically judge and trigger the alarm through the model interface, accurately locate the fire location and timely handle the disaster and evacuate the crowd. In terms of BIM technology in equipment maintenance and prefabricated buildings, the operation and maintenance personnel can obtain the information of component quality through the use of RFID tags, as well as the relevant information of transporters, installation workers, construction workers and production workers, so as to quickly trace the responsibility of prefabricated construction quality. BIM technology can also use embedded RFID tags to effectively monitor, analyze and 
detect the use process of the whole prefabricated building, so as to accurately locate the high energy consumption parts and find the best treatment method.

\subsection{Prefabricated buildings}

\section{Definition of prefabricated building}

Prefabricated building is considered as a kind of green building. In fact, most of its use is promoted by sustainable technology. It is a new architectural concept under the development of science and technology [14]. Compared with the traditional building type, this building type greatly reduces the net weight of the building and improves the efficiency in construction. Its core purpose is to use the optimal design scheme to carry out the construction and assembly of building components in the shortest time, but correspondingly, in order to achieve the overall quality requirements, in the actual construction process, the building type must ensure that each building assembly component has a good running state, only in this way can the safety and quality of prefabricated buildings be ensured $[15,16]$. The building assembly process is shown in Fig. 1

\section{The core of prefabricated building}

Prefabricated building is just like building block building. This kind of building is to assemble the beams, floors, columns, walls and other components on the assembly line on site to build a house, which realizes the factory manufacturing, construction assembly, function modernization and design diversification. This is the "three modernizations" (industrialization, informatization, standardization) method to manage, build and use buildings, which makes the construction industry change from traditional to modern ways of science and technology, saving, environmental protection, intensive, green and so on [17]. "Integration" is the core of prefabricated building, while the main line of "integration" is informatization. Through the role of BIM technology on prefabricated building, it can effectively control and manage the life cycle of prefabricated building, deepen the design of components, optimize the design scheme and operate and maintain the assembly simulation building in the production, transportation and use of components, improve the efficiency of assembly building production, construction and design, realize the industrialization of building flute and promote the promotion of prefabricated building.

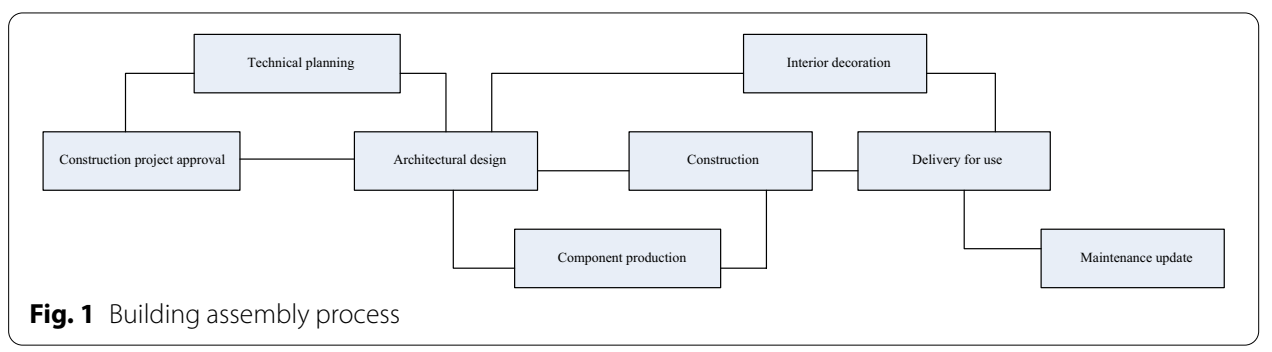


3. Influencing factors of prefabricated building

1. Due to process factors, in the manufacturing and production of prefabricated buildings, problems such as slurry leakage and dislocation often occur due to unreasonable splicing of formwork. Therefore, it is necessary to clarify the specific parameters and installation position of the formwork before pouring concrete to ensure that the bolts meet the tightness of relevant standards. If the formwork bolts are not fixed properly, the formwork bolts shall be fixed. Then concrete vibration compaction cannot meet the requirements, which leads to the emergence of a large number of cracks in the concrete watering maintenance [18]. In addition, if the thickness of the interlayer is not strictly controlled, it will increase the thickness of the mortar layer, cause obvious changes in the position of the concrete, or cause the slurry layer to become thinner, so that a lot of air enters into the joint surface, and the setting out is not accurate, resulting in different elevations.

2. Material factor, in the construction of prefabricated buildings, the components used must be made. If the components do not meet certain standards or are put into use without inspection, it is difficult to guarantee the performance of prefabricated buildings. In addition, there are many aspects that affect its performance, so we must pay enough attention to them. If there is no special personnel to do special inspection on performance and quality before construction, it is not clear whether the quality of materials meets the construction requirements.

3. Personnel and construction machinery factors, if the personnel and construction machinery can be reasonably controlled, then the quality of construction will be guaranteed in essence. Therefore, the construction unit should strictly manage and control the construction personnel and construction machinery. Different from the original building form, the configuration of construction machinery and prefabricated construction personnel will change obviously, so the person in charge should manage the construction according to the actual situation, so as to ensure the significant improvement of quality. Different machinery and hoisting equipment should be used in strict accordance with relevant requirements, so as to give full play to the performance advantages of these machines [19].

4. Management factors: at present, construction enterprises need to pay more attention to the management work, and the management method adopted is fine. At the same time, in the actual construction process, the management personnel must combine with the actual situation to improve and formulate the management plan, and flexibly adjust the management strategy under the operation conditions, so as to ensure the effective improvement of the management level and meet the site construction [20]. However, after the in-depth analysis of prefabricated construction, it will be found that the quality of management personnel needs to be improved. Otherwise, innovative ideas cannot be applied in management, which will lead to the failure of management to play its real value and role. Moreover, without sound management system and perfect construction rules, it cannot provide accurate basis for management work. 
The design value of shear bearing capacity shall be calculated as follows:

$$
V=0.6 f_{g} p+0.8 N
$$

The design value of shear bearing capacity of horizontal joint of prefabricated shear wall should be calculated according to the following formula

$$
V=0.6 f_{g} p+0.6 N
$$

Under the condition of building compression, the design value of shear bearing capacity of horizontal joint at the bottom of precast column shall be calculated according to the following formula

$$
\begin{aligned}
& V=0.8 N+1.65 p \sqrt{f_{c} f_{y}} \\
& V_{n}=0.8 N+1.65 p \sqrt{f_{c} f_{y}\left[1-\left(\frac{n}{p f_{y}}\right)^{2}\right]}
\end{aligned}
$$

For the sustainable design status of buildings

$$
V=0.07 f_{c} A_{c}+0.10 f_{c} A_{l}+1.6 A_{s} \sqrt{f_{c} f_{y}}
$$

When the building is under pressure

$$
V=0.04 f_{c} A_{c}+0.03 f_{c} A_{k}+1.62 A_{s} \sqrt{f_{c} f_{y}}
$$

\subsection{Material management}

Material management is the general name of a series of organization, control, planning and other management activities for the acceptance, supply, purchase, rational use, distribution, storage, comprehensive utilization and saving of various materials required by enterprises in production and operation activities [21, 22]. It can not only coordinate the relationship between the functional departments within the enterprise, but also control the materials from the overall perspective of the enterprise, so as to achieve the economic benefits of fast turnover, low consumption, good supply and low cost, so as to ensure the smooth production of the enterprise. There are four basic activities in material management: first, forecasting the amount of materials used to make material supply plan; second, purchasing, organizing the source of goods or adjusting materials; third, the storage, acceptance, distribution and collection of materials; fourth, accounting, inventory and statistics of materials [23, 24]. With the development of computer technology and manufacturing industry and the flexible use of quantitative analysis methods, the development from simple material reserves management to just in time material management, from manual development to informatization and automation MRP system, from professional department management to comprehensive management [25]. 
In the material management mode, we assume that there are $n$ samples of influencing factors of integrated management, and each sample has $\mathrm{p}$ variables. The $n \times p$ matrix is obtained as follows:

$$
\begin{aligned}
& X=x_{11}, x_{12}, \ldots, x_{1 p} \\
& X=x_{21}, x_{22}, \ldots, x_{2 p} \\
& X=x_{n 1}, x_{n 2}, \ldots, x_{n p}
\end{aligned}
$$

Let $X_{1}, X_{2}, \ldots X_{P}$ be the original variables and $Q_{1}, Q_{2}, \ldots, Q_{M}(m \leq P)$ be new variables, then the linear relationship between them is as follows:

$$
\begin{aligned}
& q_{1}=l_{11} x_{1}+l_{12} x_{2}+\cdots+l_{1 p} x_{p} \\
& q_{m}=l_{m 1} x_{1}+l_{m 2} x_{2}+\cdots+l_{m p} x_{p}
\end{aligned}
$$

where $l_{i j}$ is the load of the original variable on each principal component, and the new variable indexes $q_{1}, q_{2} \ldots$ are called the first, second,... principal components of the original variable index, respectively, and $q_{1}$ and $q_{2}$ are independent of each other. The essence of principal component analysis is to determine the load $l_{m}$ of the original variable $x_{1}$ on each principal component $q_{1}$, which are the eigenvectors corresponding to the m larger eigenvalues $\lambda_{i}$ of the correlation matrix, and standardize the data samples as follows:

$$
X_{i j}=\frac{X_{i j}-\bar{X}_{j}}{S_{j}^{-2}}
$$

where

$$
\begin{aligned}
& X_{\mathrm{j}}=\frac{1}{n} \sum_{1}^{n} X_{i j} \\
& S_{j}=\frac{1}{n-1} \sum_{1}^{n}\left(X_{i j}-\bar{X}_{j}\right)
\end{aligned}
$$

Based on the above calculation, the cumulative variance contribution rate of the first $k$ factors is calculated as follows:

$$
a_{k}=\sum_{i=1}^{k} \frac{q S_{i}^{2}}{\lambda_{i p}}
$$

where $p$ is the number of factors, and the value of the $i$-th factor on the $i$-th sample is expressed as follows:

$$
G_{i j}=a_{k}\left(M_{j 1} X_{1 i}+M_{j 2} X_{2 i}+\cdots+M_{j p} X_{p i}\right)
$$


In formula (7), $M_{j 1}, M_{j 2}, \ldots \mathrm{M}_{j p}$ are the factor value coefficients between the $j$ th factor and the $p$-th original variable, and the factor score can be regarded as the weight of each variable, and the sum of $M_{j 1}, M_{j 2}, \ldots M_{\text {jpde }}$ is calculated as follows:

$$
F_{i}=a_{k}\left(M_{j 1} X_{1}+M_{j 2} X_{2}+\cdots+M_{j p} X_{p}\right)
$$

\section{Experimental}

\subsection{Subjects}

In this paper, sand table simulation is used to carry out prefabricated building test. BIM technology is used in the whole process of the implementation of one building. The other two buildings are started at the same time. One building has no auxiliary technology and adopts the conventional construction method. The other one is set as the control group and adopts the combination of BIM and wireless communication. In addition to different technologies, other relevant parameters, such as personnel and location, were selected to compare the gap between the two buildings. The key points of assembly technology are shown in Fig. 2

As the ultimate goal of enterprise survival is to maximize the value of the enterprise, profit is the most critical link. Under the condition of a certain price, the minimum cost can maximize the profit. The purpose of material management is to enable enterprises to meet the needs of user departments in an appropriate, timely, appropriate quality and price with the ideal and rapid process and the lowest cost, so as to reduce the loss and maximize the efficiency of materials. The main research direction of this paper is the difference in material management between the two buildings.

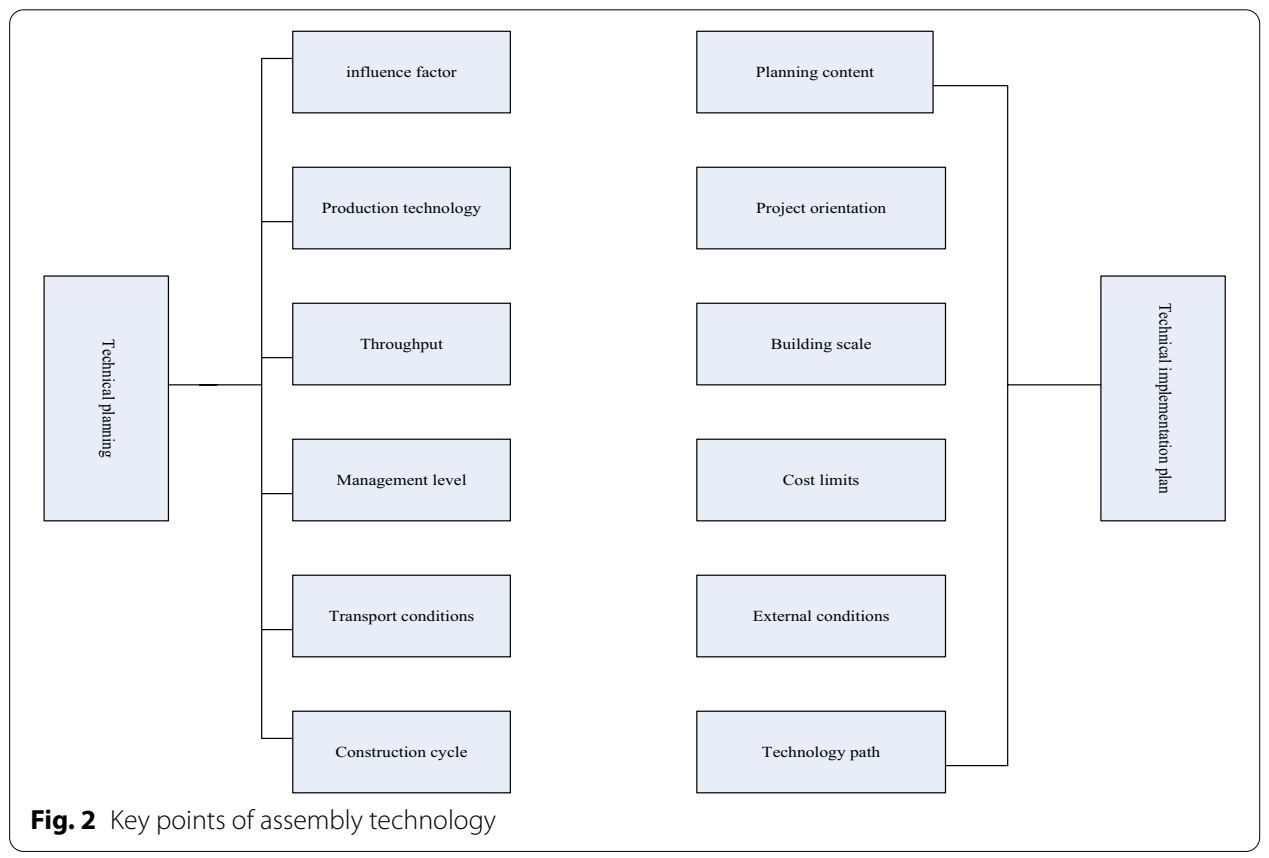




\subsection{Experimental steps}

The building process of prefabricated building can be divided into three stages: design stage, production stage and construction stage. However, in terms of material management, the design phase does not involve material issues, so material management is mainly concentrated in the production stage and construction stage.

The problems involved in material management in production stage and construction stage include supplier selection, product procurement, transportation mode selection, procurement batch and frequency, material quality, warehouse area and raw material scrap rate. In the sand table simulation experiment of this paper, the selection of suppliers is set as the same, but according to the different purchase quantity, the unit price and transportation cost are different. Whether the purchase quantity is appropriate or not is related to the number of inventory turnover. Generally speaking, the higher the inventory turnover times, the more sufficient the utilization of funds, the better the efficiency of inventory management. The lower the scrap rate is, the better the quality of the materials is. The more surplus materials are left after the production or use of raw materials, which indicates that the more cost is wasted.

\subsection{Evaluation index}

The material management process of construction industry can be roughly divided into three categories: procurement process, warehouse management and material quality monitoring. First of all, in terms of purchasing process, the purchasing efficiency and capital occupation can be expressed by the number of inventory turnover.

The monitoring theory is derived from the nonlinear partial differential equation of Taylor series expansion motion:

$$
\frac{a^{2} R}{a t^{2}}=b_{o}^{2}\left[1+\frac{w^{\prime \prime}}{w^{\prime}} \frac{a u}{a d}+\ldots\right] \frac{a^{2} R}{a d^{2}}
$$

Equations related to elastic constants of nonlinear parameters:

$$
\eta_{2}=-\frac{w^{\prime \prime}}{2 w^{\prime}}
$$

The variation of the equation is:

$$
\frac{a^{2} R}{a t^{2}}=b_{o}^{2}\left[1-2 \eta_{2} \frac{a u}{a d}+\ldots\right] \frac{a^{2} R}{a d^{2}}
$$

The solution of the equation is:

$$
R=R_{1} \cos (q x-w d)-\frac{1}{4} \eta_{2} q^{2} R_{2} x \sin 2(q x-w d)+\ldots
$$

The relationship between $R_{2}$ and $R_{3}$ is obtained

$$
\begin{aligned}
& R_{2}=\left(\eta_{2} / 4\right) d^{2} R_{1}^{2} x \\
& R_{3}=\left(\eta_{2}^{2} / 8\right) d^{4} R_{1}^{3} x^{2}
\end{aligned}
$$


Table 1 Assembly differences

\begin{tabular}{llll}
\hline & BIM assembly & Traditional assembly & $\begin{array}{l}\text { Control } \\
\text { group }\end{array}$ \\
\hline Production stage & 6 & 4 & 7 \\
Construction stage & 3 & 2 & 4 \\
\hline
\end{tabular}

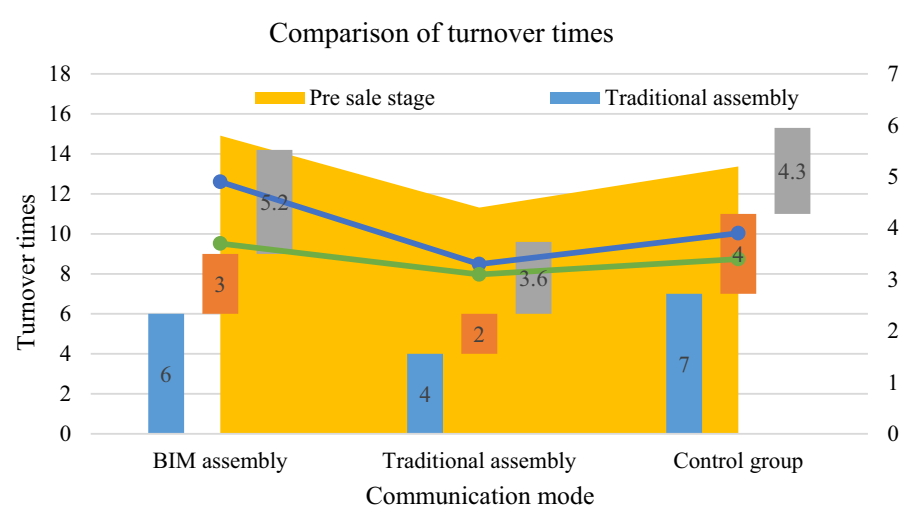

Fig. 3 Comparison of inventory turnover times of the two methods

$A 1, A 2$ and $A 3$ are expressed as

$$
\begin{aligned}
& \frac{A 2}{A_{1}^{2}}=\left(\frac{\eta_{2}}{4}\right) d^{2} x \\
& \frac{A_{3}}{A_{1}^{3}}=\left(\frac{\eta_{3}}{6}\right) d^{3} x
\end{aligned}
$$

\section{Results and discussion}

\subsection{Procurement differences between the two technologies}

1. Comparison of inventory turnover times

The number of inventory turnover is the ability to maximize the use of enterprise surplus funds when meeting the daily needs of materials. High inventory turnover times can not only improve the utilization rate of funds, but also reduce the accumulation of materials. Because BIM technology can make the purchasing personnel know the materials and quantity needed by each production department and construction part in time, the material turnover times of the prefabricated building material management method based on BIM technology is higher than that of the conventional prefabricated building material management method, and the data are shown in Table 1.

It can be seen from Fig. 3 and 4 that in the production stage, the average inventory turnover times of the assembly building material management method based on BIM technology is 6 , and that of the conventional method is 4 . However, in the construction stage, the difference between the two methods is narrowed. The turnover times of the 


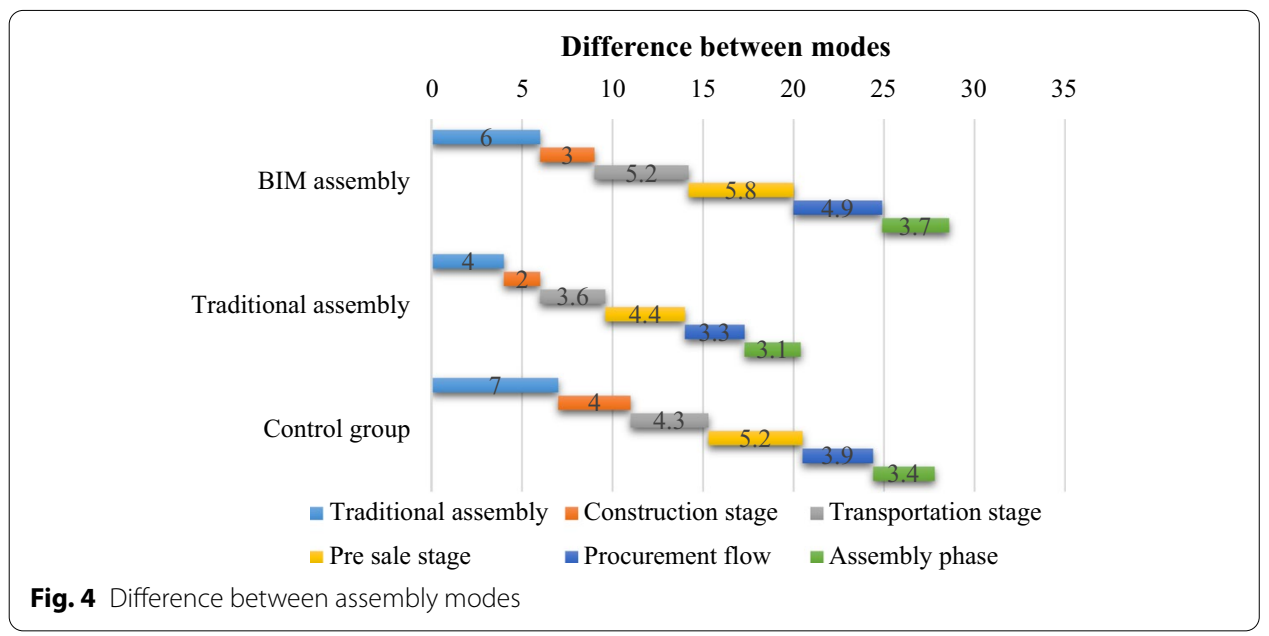

Table 2 Comparison of transportation costs between the two methods in the construction process

\begin{tabular}{lll}
\hline & Unit price per purchase & Transportation times \\
\hline BIM technology & 5.32 & 15 \\
Conventional method & 5.11 & 12 \\
Control group & 6.1 & 14 \\
\hline
\end{tabular}

assembly building material management method based on BIM technology is reduced to 3 , and the turnover times of the conventional method is reduced to 2 . Under the combination of BIM and wireless communication, the inventory turnover of the control group reaches 7 times and 4 times in the construction stage, which is higher than that of BIM assembly.

\section{Transportation cost comparison}

The inventory turnover times of prefabricated building materials management method based on BIM technology is high, which brings about the problem of rising transportation cost. On the one hand, the transportation times increase, and the transportation oil cost and the loss of fixed assets such as materials and vehicles increase. On the other hand, if the quantity of each purchase is large, the cash discount or commercial discount given will increase. Therefore, the conventional method can indirectly reduce the total cost in this respect. The specific transportation cost is shown in Table 2.

As shown in Fig. 5, the unit price of prefabricated building material management method based on BIM technology is higher than that of prefabricated building with traditional method. From the perspective of transportation times, the transportation management method of prefabricated building materials based on BIM technology is more than three times of the traditional method. After combining with wireless communication, the transportation times is far higher than the traditional method. Therefore, BIM is superior to the traditional method in terms of transportation cost. 


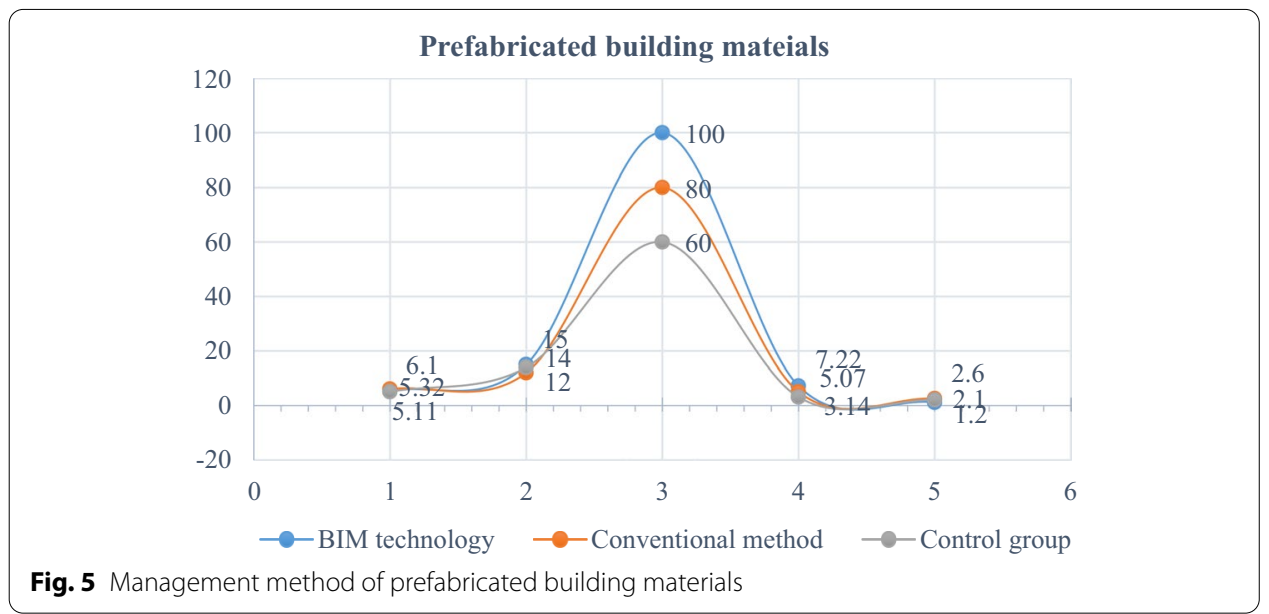

Table 3 Warehouse occupancy between the two methods

\begin{tabular}{llll}
\hline & BIM assembly (\%) & Traditional assembly (\%) & $\begin{array}{l}\text { Control } \\
\text { group } \\
\text { (\%) }\end{array}$ \\
\hline Production stage & 78 & 42 & 68 \\
Construction stage & 91 & 54 & 77 \\
\hline
\end{tabular}

\subsection{Storage differences between the two technologies}

1. Warehouse occupancy comparison

The occupancy rate of the warehouse is closely related to the cost. The low occupancy rate of the warehouse can reduce the use of the warehouse and reduce the warehouse rent of the construction project. From the above material turnover times, it can be seen that in the construction process of the prefabricated building material management method based on BIM technology, the turnover speed of the materials is fast, so the occupancy rate of the warehouse is low. The comparison of the warehouse occupancy rate of the two methods in the construction process is shown in Table 3.

As can be seen from Figs. 6 and 7, the warehouse occupancy rate of the prefabricated building materials management method based on BIM technology is $78 \%$ and $42 \%$ lower than that of the traditional method, and the effect of combining BIM with wireless communication is better than that of the traditional method.

2. Comparison of the proportion of surplus useless materials in total purchased materials

In the process of construction, surplus materials will inevitably be produced. The more surplus materials, the more the cost. The comparison of the ratio of the surplus useless materials in the total purchased materials of the two methods in the construction process is shown in Table 4. 


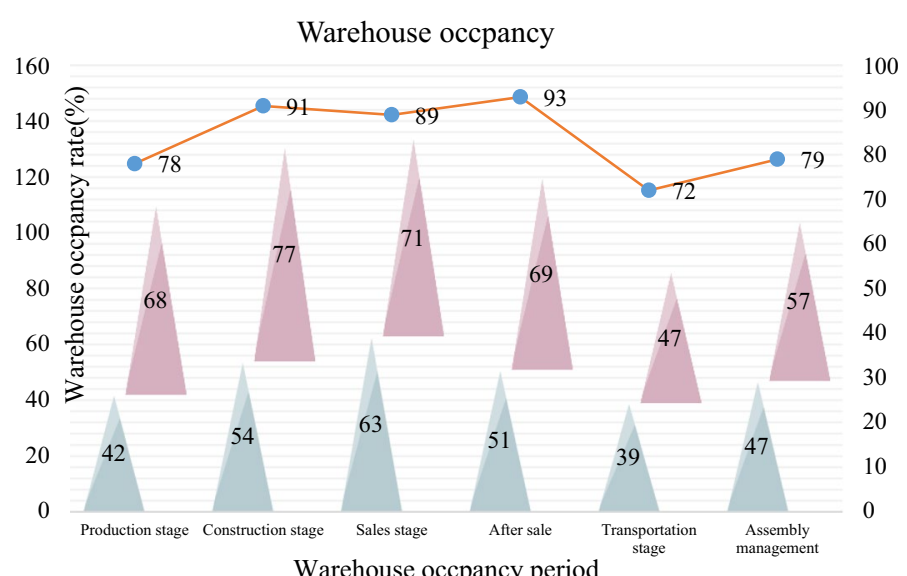

Fig. 6 Warehouse occupancy rate (\%)

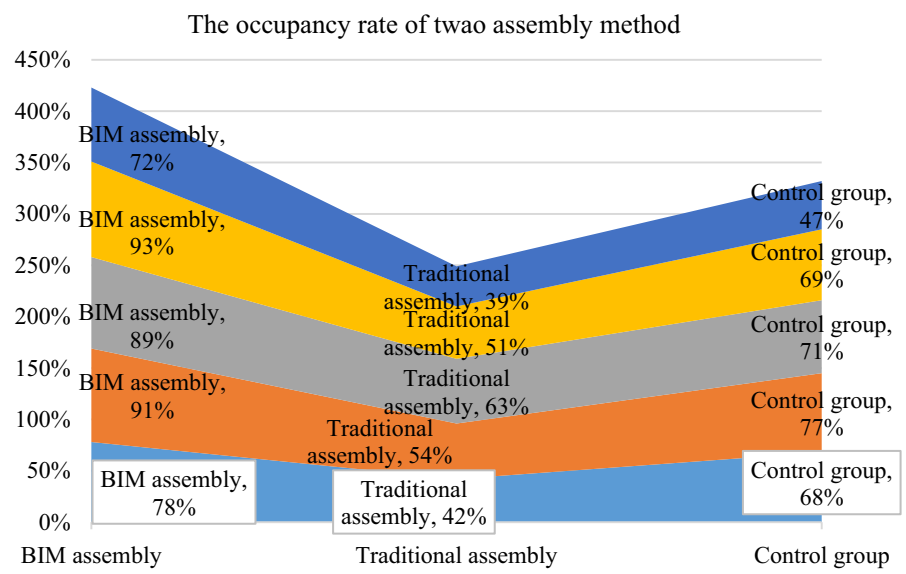

Fig. 7 The occupancy rate of two assembly methods

Table 4 Spot check of qualified rate of materials

\begin{tabular}{lll}
\hline & BIM assembly (\%) & $\begin{array}{l}\text { Traditional } \\
\text { assembly } \\
\text { (\%) }\end{array}$ \\
\hline Production stage & 6 & 3 \\
Construction stage & 4 & 2 \\
\hline
\end{tabular}

It can be seen that the proportion of surplus useless materials in the warehouse in the production stage and construction stage of the prefabricated building material management method based on BIM technology accounts for $6 \%$ and 3\% of the total purchased materials, respectively, while that of the conventional method in the production stage and construction stage accounts for $4 \%$ and $2 \%$, respectively. 


\subsection{Material quality difference}

The quality control of materials is also an important link in material management. We use the method of sampling survey to test the purchased materials of prefabricated buildings under two technical conditions and calculate the failure rate of all materials. The sampling survey results are shown in Table 5.

It can be seen from Table 5 that the material failure rate of prefabricated building material management method based on BIM technology is $2 \%$, and that of conventional method is $5 \%$. The scrapping of materials in the process of use is also a part of the cost. It is necessary to minimize the occurrence of material scrapping in the material management. The comparison of the two methods of material scrap rate in the construction process is shown in Table 6.

We compared the production cost changes of the same factory in different management modes from 2015 to 2019, as shown in Fig. 8.

It can be seen from Fig. 9 that the material scrap rate in the construction stage is higher than that in the production stage. The material scrap rate of the fabricated building

Table 5 Results of failure rate in material sampling survey

\begin{tabular}{llll}
\hline & Sample size & Number of failed & $\begin{array}{l}\text { Total } \\
\text { failure } \\
\text { rate (\%) }\end{array}$ \\
\hline BIM technology & 100 & 2 & 2 \\
Conventional method & 100 & 5 & 5 \\
\hline
\end{tabular}

Table 6 Results of failure rate in material sampling survey

\begin{tabular}{llllll}
\hline & $\mathbf{2 0 1 5}$ & $\mathbf{2 0 1 6}$ & $\mathbf{2 0 1 7}$ & $\mathbf{2 0 1 8}$ & $\mathbf{2 0 1 9}$ \\
\hline BIM technology & 11,176 & 12,866 & 15,443 & 18,920 & 20,368 \\
Conventional method & 15,324 & 17,536 & 19,758 & 21,871 & 25,369 \\
Control group & 10,235 & 11,278 & 14,336 & 16,784 & 18,952 \\
Change ratio & $14.7 \%$ & $15.1 \%$ & $21.3 \%$ & $19.4 \%$ & $17.6 \%$ \\
\hline
\end{tabular}

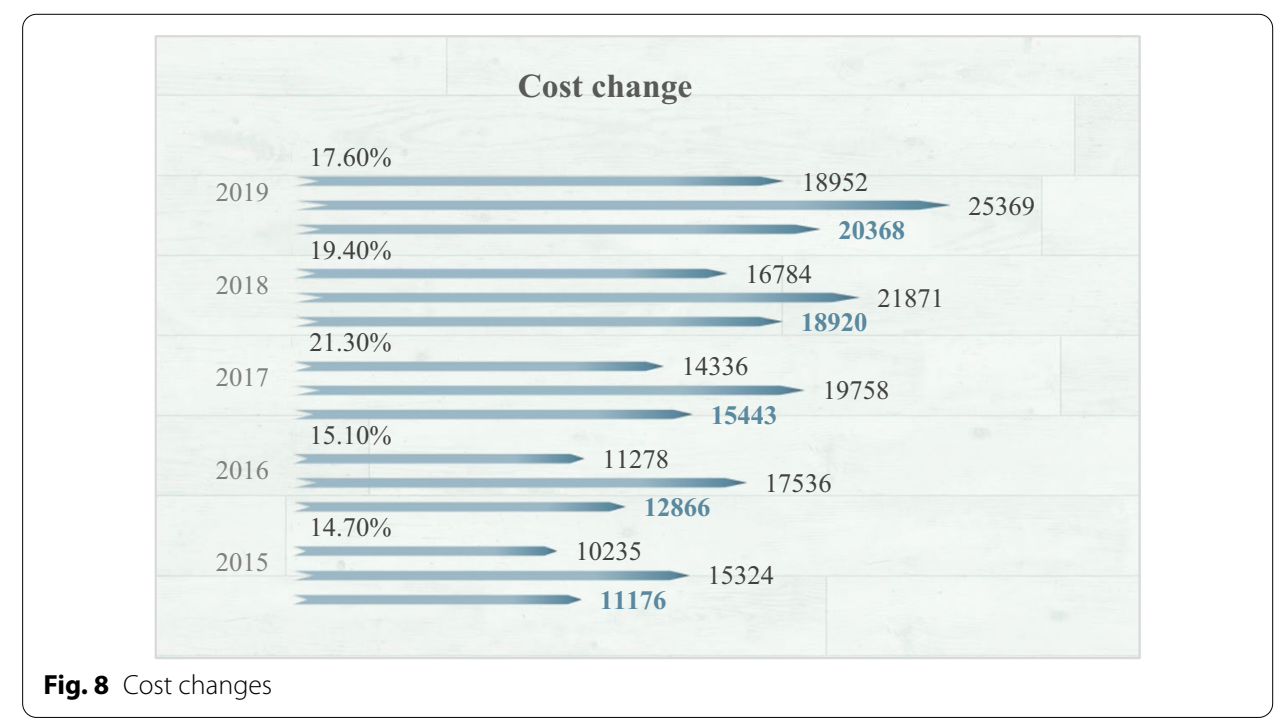




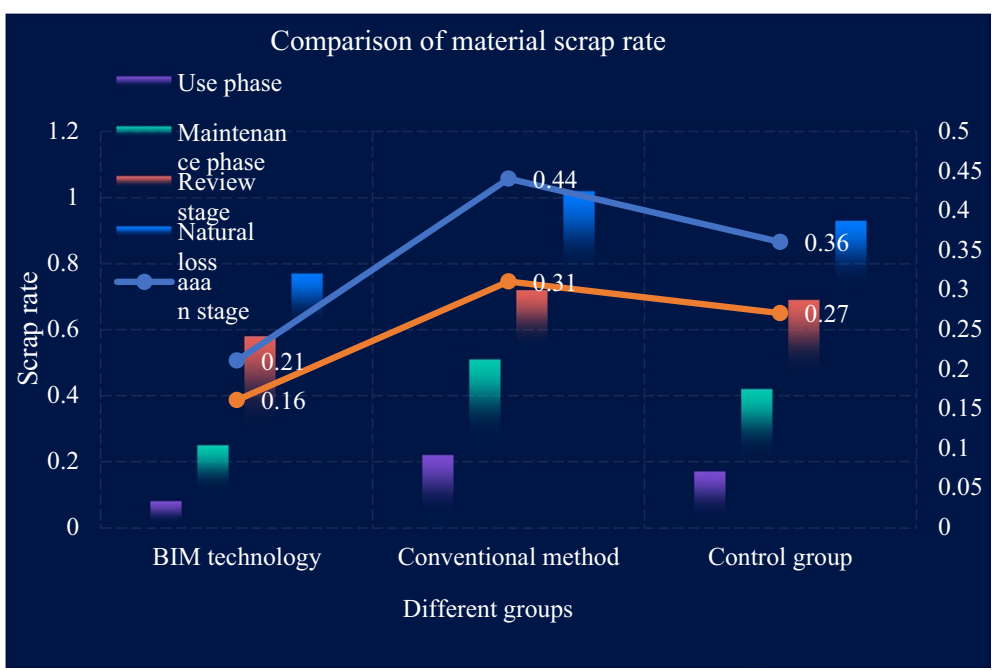

Fig. 9 Comparison of material scrap rate of two methods in construction process

material management method based on BIM technology is always lower than that of the conventional method, and the scrap rate of the control group is also lower than that of the BIM group. This shows that the combination of BIM and wireless communication can achieve better results.

\section{Conclusions}

With the rapid development of modern social communication technology, both wireless communication and wired communication technology have been developed rapidly. However, compared with wired communication technology, wireless communication technology has more advantages. Through wireless communication, the communication environment limitation rate is reduced, and the communication space is expanded. To a certain extent, this improves the efficiency and technical level of industrial production and makes the management mode of building materials more scientific. Through the update of wireless communication technology, improve the quality of wireless communication, and better provide services for all walks of life, in order to improve the management level and provide the basis for the improvement of final work efficiency.

The traditional material management mode mainly relies on the combination of manual scheduling and forklift truck, which requires a large number of manual workers to participate in the operation, and cannot cooperate with each other in information input, equipment operation, inspection and detection. Most of them stay in paper-based operation. In the traditional foundry plant, the process sheet is easy to be polluted or damaged in the process transfer project, resulting in unclear identification. At the same time, it is difficult to input and modify all kinds of processing parameters. The workpiece may not match with the process sheet. All data processing almost depends on manual collection, input, sorting and analysis, which easily causes information delay and distortion. In this paper, sand table simulation is used to carry out the prefabricated building experiment. One of the buildings uses BIM technology in the whole process of implementation, and the other building does not use any auxiliary technology, but adopts 
conventional construction methods. Then, the traditional material management and the material management under BIM technology are compared and studied.

Through the detailed analysis of the two methods, the results show that the proportion of surplus useless materials in the warehouse of BIM technology in the production stage and construction stage is $6 \%$ and $3 \%$, respectively, while that of the conventional method in the production stage and construction stage is $4 \%$ and $2 \%$, respectively. Therefore, intelligent logistics under BIM is not only accurate in life, but also can save time and effort. However, in the future, the development of intelligent logistics technology still needs a lot of research and technology promotion. The transformation of traditional small workshop factory logistics management mode is imminent. The development of intelligent logistics needs the support of computer system and information flow. It is necessary to design the organization structure, production process and process mode reasonably.

\section{Abbreviations}

BIM: Begin of information marker; 3D: Three dimensions; 4D: Four dimensions; 5D: Five dimensions; RFID: Radiofrequency identification devices; HVAC: High-voltage alternating current; MRP: Material requirements planning.

\section{Acknowledgements}

The authors thank the editor and anonymous reviewers for their helpful comments and valuable suggestions.

\section{Authors' contributions}

All authors take part in the discussion of the work described in this paper. All authors read and approved the final manuscript.

\section{Funding}

This project has no funding support.

\section{Declarations}

\section{Consent for publication}

Approved.

\section{Competing interests}

There is no potential competitive advantage in our paper. All the authors have reviewed the manuscript and agreed to submit it to your magazine. We confirm that the contents of the manuscript have not been published or submitted for publication elsewhere.

Received: 3 September 2020 Accepted: 22 March 2021

Published online: 04 May 2021

\section{References}

1. Q. Wang, Z. Guo, T. Mei et al., Labor crew workspace analysis for prefabricated assemblies' installation: a 4D-BIMbased approach. Eng. Constr. Archit. Manag. 25(3), 00-00 (2018)

2. Y. Yan, W. Xianzhong, Research and application of BIM technology in the design of prefabricated and assembled concrete structures. Agro Food Ind. Hi Tech. 28(1), 542-546 (2017)

3. G. Zhanglin, G. Si, L. Jun-E, Application of BIM technology in prefabricated buildings. IOP Conf. Ser. Earth Environ. 81(1), 012139 (2017)

4. Y.F. Shi, S. Kang, P.P. Song, Research on development countermeasures of prefabricated building in china based on SWOT analysis. Constr. Econ. 12(4), 165-172 (2016)

5. H. Li, A. Zhao, D. Zhang et al., Research on building software usage model based on UML model. Int. J. Syst Assur. Eng. Manag. 9(3), 1-9 (2018)

6. S. Mostafa, K.P. Kim, V.W.Y. Tam et al., Exploring the status, benefits, barriers and opportunities of using BIM for advancing prefabrication practice. Int. J. Constr. Manag. 20(2), 146-156 (2020)

7. R. Bortolini, C.T. Formoso, D.D. Viana, Site logistics planning and control for engineer-to-order prefabricated building systems using BIM 4D modeling. Autom. Constr. 98, 248-264 (2019)

8. M.M. Singh, A. Sawhney, A. Borrmann, Integrating rules of modular coordination to improve model authoring in BIM. Int. J. Constr. Manag. 19(1), 15-31 (2019)

9. O.O. Akinade, L.O. Oyedele, S.O. Ajayi, et al. Designing out construction waste using BIM technology: stakeholders' expectations for industry deployment. J. Clean Prod. 180, 375-385 (2018) 
10. F. Lindblad, K. Lehman, E. Aggerstam, A comparative study of the environmental impact from transportation of prefabricated building elements using wood or concrete. Int. J. Eng. Technol. 11(3), 154-161 (2019)

11. X.J. Li, Research on investment risk influence factors of prefabricated building projects. J. Civ. Eng. Manag. 26(7), 599-613 (2020)

12. C. Nan, Z. Jie, Estimation of environmental damages of cement building and environmental benefits of prefabricated building: a case study based on a residential project in Henan province, China. Nat. Environ. Pollut. Technol. 19(2), 721-728 (2020)

13. D. Zou, C. Sun, Analysis for thermal performance and energy-efficient technology of prefabricated building walls. Int. J. Heat Technol. 38(1), 269-273 (2020)

14. Y. Sun, J. Liu, B. Xia et al., Study on carbon emission evaluation of prefabricated building at materialization. Stage Shenyang Jianzhu Daxue Xuebao (Ziran Kexue Ban). J. Shenyang Jianzhu Univ. (Nat. Sci.) 34(5), 881-888 (2018)

15. J.P. Couto, P. Mendonca, A.P. Reis, Prefabricated building systems: evaluation of the construction practitioners' perception on the environmental and economic benefits. Environ. Eng. Manag. J. 17(9), 2103-2115 (2018)

16. K.T. Wan, H. Zhu, T.Y.P. Yuen, et al. Development of low drying shrinkage foamed concrete and hygro-mechanical finite element model for prefabricated building fasade applications. Constr. Build. Mater. 165, 939-957 (2018)

17. J.G.B. Wesz, C.T. Formoso, P. Tzortzopoulos, Planning and controlling design in engineered-to-order prefabricated building systems. Eng. Constr. Archit. Manag. 25(2), 134-152 (2018)

18. R. Griffith, Implementing offsite construction and prefabricated building systems. Des. Cost Data 62(3), 50-50 (2018)

19. S. Qianqian, Design of prefabricated old-age building based on modularization: a case study of institutional elderly houses design in Taigou village, Xi'an City. J. Landsc. Res. 10(05), 87-90 (2018)

20. K. Zhang, S. Tong, J. Zhao et al., Control method of shaft and hole mating based on convolution neural network in assembly building prefabricated components. IOP Conf. Ser. Mater. Sci. Eng. 399(1), 012061 (2018)

21. Q. Tang, Z. Liu, W. Chen et al., The application of BIM in small and medium-sized smart substation-a case study of prefabricated building design. IOP Conf. Ser. Earth Environ. Sci. 186(5), 012054 (2018)

22. Y.Teng, K. Li, W. Pan, et al. Reducing building life cycle carbon emissions through prefabrication: evidence from and gaps in empirical studies. Build. Environ. 132, 125-136 (2018)

23. Z. Yuan, C. Sun, Y. Wang, Design for manufacture and assembly-oriented parametric design of prefabricated buildings. Autom. Constr. 88, 13-22 (2018)

24. I. García-Pereira, C. Portalés, J. Gimeno et al., A collaborative augmented reality annotation tool for the inspection of prefabricated buildings. Multimedia Tools Appl. 79(4), 1-19 (2019)

25. W. Ferdous, Y. Bai, T.D. Ngo, et al. New advancements, challenges and opportunities of multi-storey modular buildings - a state-of-the-art review. Eng. Struct. 183, 883-893 (2019)

\section{Publisher's Note}

Springer Nature remains neutral with regard to jurisdictional claims in published maps and institutional affiliations.

Xinhua Wu was born in Jining, Shandong, P.R. China, in 1978. He received the Master degree from Shandong University of Science and Technology, P.R. China. Now, he works in College of Resources, Shandong University of Science and Technology. His research interest includes construction project management, civil engineering.

\section{Submit your manuscript to a SpringerOpen ${ }^{\circ}$ journal and benefit from:}

- Convenient online submission

- Rigorous peer review

- Open access: articles freely available online

- High visibility within the field

- Retaining the copyright to your article

Submit your next manuscript at $>$ springeropen.com 